\title{
GCU
}

Glasgow Caledonian

University

University for the Common Good

\section{Gender invariance and psychometric properties of the Non-Productive Thoughts Questionnaire for Children}

Kocsel, Natália; Mónok, Kata; Szabó, Edina; Morgan, Antony; Reinhardt, Melinda; Urbán, Róbert; Demetrovics, Zsolt; Kökönyei, Gyöngyi

Published in:

Assessment

DOI:

$10.1177 / 1073191117706140$

Publication date:

2019

Document Version

Author accepted manuscript

Link to publication in ResearchOnline

Citation for published version (Harvard):

Kocsel, N, Mónok, K, Szabó, E, Morgan, A, Reinhardt, M, Urbán, R, Demetrovics, Z \& Kökönyei, G 2019,

'Gender invariance and psychometric properties of the Non-Productive Thoughts Questionnaire for Children', Assessment, vol. 26, no. 8, pp. 1480-1491. https://doi.org/10.1177/1073191117706140

\section{General rights}

Copyright and moral rights for the publications made accessible in the public portal are retained by the authors and/or other copyright owners and it is a condition of accessing publications that users recognise and abide by the legal requirements associated with these rights.

Take down policy

If you believe that this document breaches copyright please view our takedown policy at https://edshare.gcu.ac.uk/id/eprint/5179 for details

of how to contact us. 
Running head: GENDER INVARIANCE AND PSYCHOMETRIC PROPERTIES OF NPTQ-C

Gender invariance and psychometric properties of the Non-Productive Thoughts

\title{
Questionnaire for Children ${ }^{1}$
}

\author{
Natália Kocsel \\ Doctoral School of Psychology, Eötvös Loránd University, Budapest, Hungary \\ Institute of Psychology, Eötvös Loránd University, Budapest, Hungary \\ MTA-SE-NAP B Genetic Brain Imaging Migraine Research Group, Hungarian Academy of Sciences, \\ Semmelweis University, Budapest, Hungary
}

\section{Kata Mónok}

Doctoral School of Psychology, Eötvös Loránd University, Budapest, Hungary Institute of Psychology, Eötvös Loránd University, Budapest, Hungary

\section{Edina Szabó}

Doctoral School of Psychology, Eötvös Loránd University, Budapest, Hungary

Institute of Psychology, Eötvös Loránd University, Budapest, Hungary

MTA-SE-NAP B Genetic Brain Imaging Migraine Research Group, Hungarian Academy of Sciences, Semmelweis University, Budapest, Hungary

\section{Antony Morgan}

School of Health and Life Sciences, Glasgow Caledonian University, United Kingdom

\section{Melinda Reinhardt}

Károli Gáspár University of the Reformed Church, Budapest, Hungary

Institute of Psychology, Eötvös Loránd University, Budapest, Hungary

\section{Róbert Urbán}

Institute of Psychology, Eötvös Loránd University, Budapest, Hungary

\section{Zsolt Demetrovics}

Institute of Psychology, Eötvös Loránd University, Budapest, Hungary

\footnotetext{
${ }^{1}$ This is the final author version accepted by the reviewers - this version is uncorrected and before typesetting. For the published version, please visit Assessment, doi: 10.1177/1073191117706140
} 
Running head: GENDER INVARIANCE AND PSYCHOMETRIC PROPERTIES OF NPTQ-C

\author{
Gyöngyi Kökönyei \\ Institute of Psychology, Eötvös Loránd University, Budapest, Hungary \\ MTA-SE-NAP B Genetic Brain Imaging Migraine Research Group, Hungarian Academy of Sciences, \\ Semmelweis University, Budapest, Hungary
}

\title{
Author Note
}

Natália Kocsel, Doctoral School of Psychology, Eötvös Loránd University, Budapest, Hungary; Institute of Psychology, Eötvös Loránd University, Budapest, Hungary; MTA-SENAP B Genetic Brain Imaging Migraine Research Group, Hungarian Academy of Sciences, Semmelweis University, Budapest, Hungary; Kata Mónok, Doctoral School of Psychology, Eötvös Loránd University, Budapest, Hungary; Institute of Psychology, Eötvös Loránd University, Budapest, Hungary; Edina Szabó, Doctoral School of Psychology, Eötvös Loránd University, Budapest, Hungary, Institute of Psychology, Eötvös Loránd University, Budapest, Hungary; MTA-SE-NAP B Genetic Brain Imaging Migraine Research Group, Hungarian Academy of Sciences, Semmelweis University, Budapest, Hungary; Antony Morgan, School of Health and Life Sciences, Glasgow Caledonian University, United Kingdom; Melinda Reinhardt, Institute of Psychology, Károli Gáspár University of the Reformed Church, Budapest, Hungary; Institute of Psychology, Eötvös Loránd University, Budapest, Hungary; Róbert Urbán, Institute of Psychology, Eötvös Loránd University, Budapest, Hungary; Zsolt Demetrovics, Institute of Psychology, Eötvös Loránd University, Budapest, Hungary; Gyöngyi Kökönyei, Institute of Psychology, Eötvös Loránd University, Budapest, Hungary, MTA-SE-NAP B Genetic Brain Imaging Migraine Research Group, Hungarian Academy of Sciences, Semmelweis University, Budapest, Hungary. 
Running head: GENDER INVARIANCE AND PSYCHOMETRIC PROPERTIES OF NPTQ-C

Acknowledgements: Gyöngyi Kökönyei and Zsolt Demetrovics acknowledge financial support of the János Bolyai Research Fellowship awarded by the Hungarian Academy of Sciences. This work was supported by the Hungarian Scientific Research Fund (grant number: 111938).

Conflict of Interests: The authors declare that they have no conflict of interest.

Correspondence concerning this article should be addressed to Gyöngyi Kökönyei, Institute of Psychology, Eötvös Loránd University, Budapest, Hungary, 1064, Izabella street, 46. E-mail: kokonyei.gyongyi@ppk.elte.hu 
Running head: GENDER INVARIANCE AND PSYCHOMETRIC PROPERTIES OF NPTQ-C

\begin{abstract}
Perseverative cognitions - rumination and worry - can contribute to mental and somatic health problems in adolescence. Girls usually report stronger rumination or worry than boys even in earlier years across the development age spectrum. Our aim was to test the gender invariance and psychometric properties of the Non-Productive Thoughts Questionnaire for Children (NPTQ-C). Study 1 involved 1572 students (mean age=15.39 years, SD=2.26; 49\% boy) recruited representatively from local schools. We applied confirmatory factor analysis (CFA) to test the measurement model of perseverative cognitions. The gender invariance of the measurement model, and the convergent validity were analysed as well with CFA with covariates model. The original one-factor structure of NPTQ-C was supported in our adolescent sample. Gender invariance was also confirmed. The NPTQ-C indicated high convergent validity: showing positive correlations with emotional instability and emotional symptoms. In Study 2 (385 students; mean age=16.05; $\mathrm{SD}=1.23 ; 34 \%$ boy) we tested the construct validity of NPTQ-C. The applied CFA with covariates model supported the construct validity. In summary, NPTQ-C proved to be a good instrument for measuring ruminative and worrying thoughts of adolescents, which reliably measures perseverative cognitions across genders.
\end{abstract}

Keywords: rumination, worry, Non-Productive Thoughts Questionnaire for Children, gender invariance, convergent validity, psychometrics 
Running head: GENDER INVARIANCE AND PSYCHOMETRIC PROPERTIES OF NPTQ-C

Perseverative cognitions such as rumination and worry have become the main focus of much psychological research over the last three decades (Beckwe \& Deroost, 2015; Ottaviani et al., 2016) because of its importance to mental health (Aldao, Nolen-Hoeksema, \& Schweizer, 2010; Nolen-Hoeksema, 1991; Nolen-Hoeksema, Wisco, \& Lyubomirsky, 2008) and physical health (Brosschot, Gerin, \& Thayer, 2006; Jellesma, Verkuil, \& Brosschot, 2009; Kökönyei et al., 2015). Ruminative and worrying thoughts reflect the tendency to focus repetitively on negative aspects of one-self and on dysphoric mood states that relate either to past or future events and to failures (Nolen-Hoeksema, 1991; Nolen-Hoeksema et al., 2008). The repetitive occurrence of these thoughts are considered to play a significant role in internalizing disorders such as major depressive disorder (MDD) and generalized anxiety disorder (GAD) (Borkovec, Ray, \& Stober, 1998; Hsu et al., 2015; McLaughlin, Borkovec, \& Sibrava, 2007). Furthermore it is important in prolonged stress-related activation, which is also often accompanied with increased negative affects (Brosschot, Pieper, \& Thayer, 2005; Verkuil, Brosschot, de Beurs, \& Thayer, 2009).

Perseverative thoughts are usually studied in adult samples (Brosschot et al., 2006; NolenHoeksema \& Morrow, 1993), however recent research has aimed to expand the focus to younger populations (Abela, Brozina, \& Haigh, 2002; Garnefski, Rieffe, Jellesma, Terwogt, \& Kraaij, 2007; Young \& Dietrich, 2015). Abela and colleagues (2002) found that rumination predicted increases in depressive symptoms in third and seventh grade (aged 8-12 years) children, through increased levels of hopelessness and low self-esteem (Abela et al., 2002). In another study of 10 year olds (pre-adolescents), rumination and worry were also positively correlated with self-reported somatic complaints (Jellesma, 2008). 
Running head: GENDER INVARIANCE AND PSYCHOMETRIC PROPERTIES OF NPTQ-C

Rumination and worry are often distinguished from each other and are measured separately as different constructs (Hoyer, Gloster, \& Herzberg, 2009; Muris, Roelofs, Meesters, \& Boomsma, 2004; Watkins, 2004), however they share many common characteristics such as self-focused perspective, repetitiveness or intrusiveness (Fresco, Frankel, Mennin, Turk, \& Heimberg, 2002). Rumination and worry are highly correlated factors (Smith \& Alloy, 2009) and play overlapping roles in the development and maintenance of MDD and GAD (Segerstrom, Tsao, Alden, \& Craske, 2000). These findings provide a justification for the simultaneous measurement of both constructs.

A relatively new instrument the Non-Productive Thoughts Questionnaire for Children (NPTQ-C) was designed to capture simultaneously rumination and worry of children and adolescents (Jellesma et al., 2005). The NPTQ-C was developed by Jellesma and her coworkers (2005) using an elementary school sample consisted of 717 children (394 boys and 323 girls, mean age $=10.3$ years). The questionnaire contains ten items organized in a onefactor structure showing good reliability (Cronbach $\alpha=.84$ ) (Jellesma et al., 2005). Despite this NPTQ-C has been used in only a few studies (Garnefski et al., 2007; Rieffe et al., 2007) and sometimes with a different name. Rieffe et al. (2007) called it, "The Worry Questionnaire". The reliability of the NPTQ-C was proven to be good in both a Dutch and an English sample. Cronbach alpha values in these cases were found to be above 0.8 (Garnefski et al., 2007; Rieffe et al., 2007). Initial work by Rieffe at al. (2007) on validity indicated that perseverative cognitions are differently associated with the components of emotional awareness. However, it is clear that work remains to be done to evaluate the psychometric properties and factor structure of the questionnaire.

Previous studies (Nolen-Hoeksema, 2012; Nolen-Hoeksema \& Aldao, 2011) revealed gender differences in the tendency to engage in rumination or worry (girls being more like to do this than boys). Other studies have shown that these gender differences are already 
Running head: GENDER INVARIANCE AND PSYCHOMETRIC PROPERTIES OF NPTQ-C

presented at an early age, for example in second grade children (Jose \& Brown, 2008; Lopez, Driscoll, \& Kistner, 2009) and in 12-year-old preadolescents (Jose \& Brown, 2008). These compare well with well-known gender differences in depression and anxiety (McLean, Asnaani, Litz, \& Hofmann, 2011; Parker, Fletcher, Paterson, Anderson, \& Hong, 2014). Johnson and Whisman (2013) however, argued that findings from a meta-analysis show the effect sizes of the gender differences in rumination to be small, albeit the study was amongst adults. Despite findings that have shown significant differences in the usage of perseverative cognitions between men and women (Nolen-Hoeksema, 2012), little work has been carried out to test gender invariance in the context of the psychometric properties of NPTQ-C. It is therefore important to determine if the distinct responses given to the items by men and women reflect true gender differences, or are just the product of different meanings ascribed to scale items by different groups (Milfont \& Fischer, 2010). This provides the specific rationale for our research.

Two different studies were conducted, in order to answer our hypotheses. The aims of Study 1 were threefold: (a) to test the original one factor structure in a representative sample of Hungarian adolescents, (b) to test the gender invariances of the NPTQ-C, and (c) to investigate the internal consistency and convergent validity of the questionnaire. The Strength and Difficulties Questionnaire (SDQ; Goodman, Meltzer, \& Bailey, 1998) and The Big Five Questionnaire for Children (BFQ-C; Barbaranelli, Caprara, Rabasca, \& Pastorelli, 2003) were used to test the latter. The rationale for this was twofold. Firstly, conscious perseverative cognitions (e.g., rumination) have been found to contribute to prolonged physiological and psychological distress (Brosschot et al., 2006) and secondly they show a significant relationship with personality traits (e.g., neuroticism) (Roelofs, Huibers, Peeters, Arntz, \& van Os, 2008; Trapnell \& Campbell, 1999). Given that rumination and worry have already been linked to internalizing disorders (Aldao et al., 2010), we expected that NPTQ-C 
Running head: GENDER INVARIANCE AND PSYCHOMETRIC PROPERTIES OF NPTQ-C

would have a significant positive relationship with the emotional symptoms factor of SDQ. In addition, based on previous empirical and theoretical findings relating to neuroticism and rumination (Nolen-Hoeksema \& Davis, 1999; Roelofs et al., 2008), we hypothesized a significant positive relationship between NPTQ-C and emotional instability factor of BFQ-C.

In Study 2 our goal was to test the construct validity of NPTQ-C. The Ruminative Response Scale (RRS; Treynor, Gonzalez \& Nolen-Hoeksema, 2003) was used for this purpose. This instrument measures two distinguishable facets of rumination: brooding and reflective pondering. Brooding is considered to be a maladaptive process and can be described as a tendency to dwell on negative events and dysphoric mood-states. Reflective pondering (or reflection) however, seems to be a much more adaptive process, defined as an increased, non-evaluative introspection toward one's affects and mood-states (Treynor et al., 2003).

Given this existing knowledge, we expected to find a strong positive association between NPTQ-C and brooding, and a significant, but moderate relationship with reflective pondering.

\section{Method}

\section{Participants and procedure}

Participants for Study 1 were recruited from every primary and high school in one of the largest districts in Budapest, to participate in a large cross-sectional study examining the mental health of adolescents. All schools in the district (7 high schools and 14 primary schools) agreed to participate. The local government facilitated access to schools but did not play any role in the study. From each school half of the parallel classes were randomly selected. Adolescents completed the questionnaires in the classroom within one class session. The sample characteristics therefore reflect the composition of participating classes. Data collection was supervised by the authors of this study and trained undergraduate students of 
Running head: GENDER INVARIANCE AND PSYCHOMETRIC PROPERTIES OF NPTQ-C

psychology. No teaching staffs were present. Participation in the study was voluntary. All parents and students were issued with written informed consent letters; 141 parents refused permission and 178 students were absent during data collection. Altogether 1625 youth completed the questionnaires, however, 53 were excluded from the analysis due to missing data. The final representative sample comprised 1572 students (mean age=15.39; $\mathrm{SD}=2.26$ years; 770 boys (49\%) and 802 girls (51\%)).

In Study 2, adolescents were recruited from 12 Hungarian high schools by a convenience sampling method. The procedure for this study was similar to Study 1: Participants completed self-rated questionnaires in the classroom within one class session on the theme of mental and somatic health. Data collection was supervised by the authors of this study and trained undergraduate students of psychology. No teaching staffs were present. Participation in the study was voluntary. All parents and students were issued with written informed consent letters. Altogether 397 youth completed the questionnaires, however, 12 were excluded from the analysis due to missing data. The final sample comprised 385 students (mean age $=16.05$; $\mathrm{SD}=1.23$ years; boys $(34 \%)$ and girls $(66 \%))$.

Both studies were ethically approved by the Institution Review Board of Eötvös Loránd University and the work was carried out in accordance with the Declaration of Helsinki.

\section{Measures}

\section{Study 1}

Non-Productive Thoughts Questionnaire for Children (NPTQ-C) (Jellesma et al., 2005).

Perseverative trait-like thoughts were assessed by the NPTQ-C. The one-factor scale consists of 10 items such as "I am often worried"; "When I have a problem I can't stop 
Running head: GENDER INVARIANCE AND PSYCHOMETRIC PROPERTIES OF NPTQ-C

thinking about it". Participants answered on a 3-point scale, ranging from 1 to 3 ( $1=$ not true, $2=$ sometimes true, $3=$ often true) where higher scores reflected more nonproductive thoughts (except one reversed item e.g., "Problems never worry me. I just solve them.”) and lower scores indicated more maladaptive thoughts. The questionnaire was translated from Dutch to Hungarian by two independent translators and the back-translated version of the questionnaire was approved by Jellesma. The Dutch and English versions are available at http://www.focusonemotions.nl/index.php/worry-rumination-questionnaire-for-children .

The internal consistency of the original scale was good (Cronbach's $\alpha=.84$ ) (Jellesma et al., 2005).

Strength and Difficulties Questionnaire (SDQ) (Goodman et al., 1998). Self-reported psychological symptoms were measured by the Hungarian version of the Strength and Difficulties Questionnaire (Turi et al., 2013). SDQ is a 25 -item instrument with 5 items measuring each of the five scales: (1) emotional symptoms (e.g., "I worry a lot"), (2) conduct problems (e.g., "I usually do as I am told"), (3) hyperactivity/inattention (e.g., "I am easily distracted, I find it difficult to concentrate"), (4) peer relationship problems (e.g., "I get on better with adults"), (5) prosocial behaviour (e.g., "I am helpful if someone is hurt, upset or feeling ill"). Participants were asked to score the items on a scale of 0 to $2(0=$ not true, $1=$ somewhat true, $2=$ certainly true). For each subscale, the sum score ranged from 0 to 10 . Higher scores indicated more severe problems, except in the "prosocial behaviour" scale where higher ratings implied more prosocial behaviour. Internal consistency of the Hungarian version was adequate (Cronbach $\alpha$ 's were ranging from .55 to .74 ), similar to the original questionnaire (Cronbach $\alpha$ 's were ranging from .61 to .75) (Goodman et al., 1998; Turi et al., 2013). In our study, the internal consistency of the five subscales was good or satisfactory (Cronbach $\alpha$ 's were ranging from .45 to .68, see Table 4). 
Running head: GENDER INVARIANCE AND PSYCHOMETRIC PROPERTIES OF NPTQ-C

The Big Five Questionnaire for Children (BFQ-C). This instrument was developed by Barbaranelli, Caprara and Rabasca (1998) to measure a five factor model of personality in children and adolescents. The Hungarian version of the self-report BFQ-C was used and reproduced with special permission from the Publisher, OS Hungary Ltd. It consists of 65 items grouped into five factors: energy (e.g., "I like to be with others"), agreeableness (e.g., "I share my things with other people"), conscientiousness (e.g., "If I take an engagement I keep it"), emotional instability (e.g., "I worry about silly things") and openness (e.g., "I like to know and learn new things”) (Barbaranelli et al., 2003; Rózsa, 2005). Participants had to answer whether they agreed with the statements on a 5-point scale ranging from 1 (almost never) to 5 (almost always). The Hungarian adaptation of the questionnaire showed good validity and reliability (Cronbach alphas were ranging from .75-.80) (Rózsa, 2005). In our study, the internal consistency of all the five subscales was above .80 (see Table 4).

\section{Study 2}

Ruminative Response Scale (RRS) (Treynor et al., 2013). Rumination and its two facets brooding and reflective pondering were measured by the short version of RRS. The two factor scale consists of 10 items such as "What am I doing to deserve this?"; "I write down what I am thinking about and analyse it”. Items are rated on a four-point Likert type scale of 1 to 4 (1=never, $2=$ sometimes, $3=$ often, $4=$ always). The sum of the scores were calculated and used in the analysis. The internal consistency of the questionnaire was found to be good (Cronbach $\alpha$ 's .77), and is adequate in the brooding and reflective pondering subscales (Cronbach $\alpha$ 's .68 and 0.73 respectively) .

NPTQ-C described above was also used in Study 2. 
Running head: GENDER INVARIANCE AND PSYCHOMETRIC PROPERTIES OF NPTQ-C

\section{Statistical analysis}

Study 1: SPSS 22.0 and MPlus 7.3 software were used for statistical analysis in 3 steps. Firstly, confirmatory factor analysis (CFA) was applied to test the original one factor structure of the NPTQ-C. Given the robust deviation from the normal distribution we used the technique of robust weighted least square (WLSMV) estimation (Brown, 2006; Muthén \& Muthén, 1998-2010). In order to adjust for the hierarchical nature of our data we defined our dataset as type complex. This step allowed us to take into account the non-independence of our observations. The classes as clusters were incorporated in our analysis.

Multiple criteria were applied to measure the goodness of fit in the CFA. This was done in three ways. Firstly, a satisfactory degree of fit requires the comparative fit index (CFI) and the Tucker Lewis Index (TLI) to be close to .95; the model is rejected if the indices are below 90 (Brown, 2006). The root mean square error of approximation (RMSEA) was also used to assess goodness of fit. RMSEA below .05 indicates: an excellent fit: a value around .08 an adequate fit; and a value above .10 indicates a poor fit. It should be noted that closeness of model fit using RMSEA (CFit of RMSEA) and confidence intervals for the value of RMSEA are not available under WLSMV estimation. The index, weighted root mean square residual (WRMR) was also used as a method to assess the fitness of the model (Muthén \& Muthén, 1998-2010).

A second step of the analysis involved testing the invariance of the factor structure across gender using the in-built measurement invariance test in Mplus 7.3. This allowed us to compare simultaneously chi squares for a configural, metric and scalar model. In the configural model the factor loadings and intercepts are unconstrained, except the referent indicator which is fixed at 1.0 in both groups. The means of factors in the group of boys and girls are fixed at 0 , and their variances are free to vary (Bowen \& Guo, 2012). In the metric 
Running head: GENDER INVARIANCE AND PSYCHOMETRIC PROPERTIES OF NPTQ-C

model the factor loadings were equal across groups but the thresholds were allowed to differ between them. This weak or metric invariance tests whether respondents across groups attribute the same meaning to the latent construct under study. In the strong or scalar invariance model the factor loadings and thresholds are constrained to be equal across groups (Bowen \& Guo, 2012). In order to compare nested models using the WLSMV estimator, we used the DIFFTEST procedure within Mplus (Asparouhov \& Muthen, 2006) to calculate the adjusted $\Delta \chi^{2}$-test.

A third step involved reliability analysis (Cronbach's alphas) to analyse the internal consistency of the NPTQ-C. Potential errors in the estimation of reliability were eliminated with the estimation of omega coefficients.

Finally, the convergent validity of the NPTQ-C was tested with CFA with a covariates model in order to estimate the effect of each covariate on latent variables while controlling for the effect of other covariates.

Study 2: Construct validity of NPTQ-C was tested in MPlus 7.3, with CFA with covariates model controlling for the effects of age and gender.

\section{Results}

\section{Study 1}

\section{Confirmatory Factor Analysis}

The general CFA model indicated good fit to the data $(\chi 2=169.977 ; \mathrm{df}=35 ; \mathrm{p}=.0001$; $\mathrm{CFI}=.977 ; \mathrm{TLI}=.970 ; \mathrm{RMSEA}=.050$ ). Although the examination of the modification indices revealed that degree of fit could be increased if correlations of error variances were allowed: between item 5 ("When I have a problem, I can't stop thinking about it") and 7 ("When I have 
Running head: GENDER INVARIANCE AND PSYCHOMETRIC PROPERTIES OF NPTQ-C

a problem, I think about it all the time"); and between item 8 ("When I try to deal with a problem, I am worried that I will only make things worse") and 10 ("When I don't know exactly what is happening, I usually think that bad things will happen"). Allowance for the aforementioned correlations improved the degree of fit $(\chi 2=85.156 ; \mathrm{df}=33 ; \mathrm{p}=.0001$; $\mathrm{CFI}=.991 ; \mathrm{TLI}=.988 ; \mathrm{RMSEA}=.032)$ of the indices. In this modified model, all of the standardized factor loadings were above 0.5 as shown in Table 1.

\section{Measurement of invariance}

In order to determine whether the factor structure, factor loadings and thresholds of the NPTQ-C are valid in both gender groups we tested invariances. The one factor model indicated close fit to the configural model $(\chi 2=129.150 ; \mathrm{f}=66 ; \mathrm{p}=.001 ; \mathrm{CFI}=.985 ; \mathrm{TLI}=.979$; RMSEA $=.035)$. The weak or metric invariance also indicated good fit to the data $(\chi 2=144.775 ; \mathrm{f}=75 ; \mathrm{p}=.001 ; \mathrm{CFI}=.983 ; \mathrm{TLI}=.980 ; \mathrm{RMSEA}=.034)$. Finally, we also tested the strong or scalar invariance and the indices showed good fit $(\chi 2=154.759 ; \mathrm{f}=84 ; \mathrm{p}=.001$; $\mathrm{CFI}=.983 ; \mathrm{TLI}=.982 ; \mathrm{RMSEA}=.033$ ). Although comparing the metric (or weak) and scalar (or strong) invariances to the configural model we found that there were significant differences between the chi-square statistics (see Table 2).

Given these results, it is wise to follow recommendations made by Cheung and Rensvold (2002). They argue for analysis of the $\triangle \mathrm{CFI}$ and $\triangle$ RMSEA (although the latter is highly sensitive to sample size and to model complexity) before conclusions about the lack of invariance can be determined. The hypothesized invariance should only be rejected if there is a decrease of .01 or larger in CFI and/or if there is a decrease of 0.015 or larger in RMSEA (Cheung \& Rensvold, 2002; Dimitrov, 2010). Meade and colleagues recommended stronger criteria $(\triangle \mathrm{CFI} \leq 0.002)$ for measurement invariance (Meade, Johnson, \& Braddy, 2008). 
Running head: GENDER INVARIANCE AND PSYCHOMETRIC PROPERTIES OF NPTQ-C

Table 2 shows the $\triangle$ CFI in our study to be -.002 in the metric and $<.001$ in the scalar model and that the degree of the decrease does not exceed .01 . Similarly, $\triangle$ RMSEA is below 0.015. Consequently, based on more liberal fit indices there is evidence of configural, metric, and scalar invariance of the proposed CFA model across both gender groups.

\section{Reliability}

The internal consistency of the NPTQ-C was good (Cronbach's $\alpha=.83$ ), similar to the original version. To eliminate the errors in the estimation of reliability, the omega coefficient was also determined. This also indicated good internal consistency $\left(\Omega_{\text {total }}=.85\right)$.

\section{Descriptive statistics}

Means, standard deviations, Cronbach's alphas and effect sizes are shown in Table 3. We found significant differences between boys and girls in the NPTQ-C, and in all scales of SDQ. Gender differences were significant in the three scales of BFQ-C. Although the effect sizes for differences were small in magnitude. One exception was the emotional symptoms scale of SDQ and NPTQ-C where the Cohen ds were above 0.6.

Table 4 reports correlations between measures. As expected NPTQ-C showed a significant positive correlation with the emotional symptoms scale of SDQ and with emotional instability contained within BFQ-C $(r>.50)$. The negative correlation seen between perseverative thoughts and agreeableness also proved to be significant $(\mathrm{r}>-.50)$.

\section{Convergent validity}

In order to measure convergent validity, we applied CFA with a covariates model, so we could determine the effect of each observed variable on the latent variable while controlling for the effect of other variables. We tested two models. The first model was limited to age and 
Running head: GENDER INVARIANCE AND PSYCHOMETRIC PROPERTIES OF NPTQ-C

gender. The second model included all variables (gender, age, and the subscales of SDQ and BFQ-C) and these were entered together. This approach allowed us to investigate the impact of the factors of SDQ and BFQ-C on the NPTQ-C. The standardized regression coefficients are shown in Table 5.

The emotional symptoms factor of the SDQ and the emotional instability factor of BFQ-C showed the strongest positive relation with the NPTQ-C. The conduct problems factor of SDQ and energy factor of BFQ-C also had a significant but weak negative effect on the ruminative/worrying thoughts.

\section{Study 2}

\section{Descriptive statistics}

Means, standard deviations, Cronbach's alphas and effect sizes are shown in Table 6. Significant differences were found between boys and girls in the NPTQ-C, and in both subscales of RRS. The effect sizes for differences in total rumination, brooding and reflective pondering scales were small in magnitude, except the NPTQ-C where the Cohen's d was above 0.6 , similarly to Study 1 .

Correlation matrix between measures are shown in Table 7. As expected NPTQ-C showed a significant positive correlation with all the scales and total scores of RRS.

\section{Construct validity}

In Study 2 we applied CFA with covariates model, to test construct validity of NPTQ-C. We defined the non-productive thoughts as a latent variable and we investigated the effects of brooding and reflective pondering subscales of RRS on NPTQ-C. In the effects of age and gender were controlled for. The standardized regression coefficients are shown in Table 8 . 
Running head: GENDER INVARIANCE AND PSYCHOMETRIC PROPERTIES OF NPTQ-C

While the reflective pondering factor had significant but weak impact on ruminative/worrying thoughts, the brooding factor showed strong positive association with NPTQ-C.

\section{Discussion}

The two studies presented here have several important implications. In Study 1 the factor structure, the reliability and validity of the NPTQ-C measuring perseverative cognitions were supported in a representative adolescent sample. Inthis study, gender invariance of the NPTQ$\mathrm{C}$ was also confirmed. In addition, the results of Study 2 supported the good construct validity of the questionnaire.

\section{One factor structure of NPTQ-C in adolescents}

Since non-productive thoughts have significant impact on mental and physical health not only in adulthood but also in early adolescence (Abela, Vanderbilt, \& Rochon, 2004; Kökönyei et al., 2015), we tested the factor structure of NPTQ-C in a school aged sample. The confirmatory factor analysis supported the originally proposed one factor structure of NPTQ-C (Jellesma et al., 2005), showing good fit to our data. Based on modification indices, we allowed the correlations of error variances between item 5 ("When I have a problem, I can't stop thinking about it") and 7 ("When I have a problem, I think about it all the time"), and between the item 8 ("When I try to deal with a problem, I am worried that I will only make things worse") and 10 ("When I don't know exactly what is happening, I usually think that bad things will happen") in the measurement model.

\section{Gender invariances}


Running head: GENDER INVARIANCE AND PSYCHOMETRIC PROPERTIES OF NPTQ-C

Gender differences in emotion regulation strategies have been well-established (see NolenHoeksema, 2012), however it is still not clear how these differences may account for gender differences in psychopathology. Before answering this important question, it is essential to explore whether boys and girls attribute the same meanings to questionnaire items and interpret them and the underlying latent construct in the same way. Therefore, testing measurement invariance of a scale is a prerequisite of interpreting any group differences.

Measurement invariances across gender were tested to determine whether the factor structure, the factor loadings and thresholds of the NPTQ-C are valid in both gender groups. It is meaningful in every instrument to test if the different answers reflect true gender differences or just an artefact because the groups interpret the scale items differently (Milfont \& Fischer, 2010). This is particularly important in relation to rumination and worry. Evidence suggests that there are differences in the usage of these maladaptive cognitions between men and women (Nolen-Hoeksema, 2012; Nolen-Hoeksema \& Jackson, 2001), albeit the magnitude of these differences in adult samples has been shown to be fairly small (Johnson \& Whisman, 2013). Our results indicate that adolescent girls tend to have more perseverative cognitions than boys do, moreover the magnitude of this difference is not negligible (Cohens $\mathrm{d}=0.63$ ). This may infer an important moderator role of age in the gender differences found in rumination/worry.

Our results of gender invariance testing provided support for the configural model (invariant factor structure) of NPTQ-C. In contrast, given the chi-square difference statistics, there is a suggestion that invariance is not supported in the metric (variance in the factor loadings) and scalar (variance in the factor loadings and thresholds) models. On this basis we assume that NPTQ-C shows invariance only at configural level. However, given that the chisquare difference test is often criticized because of its sensitivity to the sample size and to normal distribution (Brown, 2006), additional analyses of other indices is worthwhile 
Running head: GENDER INVARIANCE AND PSYCHOMETRIC PROPERTIES OF NPTQ-C

(Dimitrov, 2010). Cheung and Rensvold (2002) recommend that $\triangle \mathrm{CFI}, \triangle \mathrm{SRMR}$ or $\triangle \mathrm{RMSEA}$ are investigated before conclusions are made about the lack of invariance. Decreases of .01 or more in CFI across the models provide more certainty that the hypothesis should be rejected (Chen, 2007). In light of these findings, NPTQ-C showed configural, metric and also scalarlevel invariances across both gender groups, indicating that NPTQ-C is a reliable instrument, which is not substantially affected by gender bias. Our results seem to concord with Carter's (2010) research who found evidence of configural gender invariance of five instruments specifically related to worry and rumination, although these conclusions were solely based on chi-square differences, and confined to adult samples (Carter, 2010; Carter \& Bates, 2013). Further studies are needed to clarify whether questionnaires measuring rumination and worry show metric or scalar gender invariance by other indices (e.g., CFI), and whether these observations are valid in adolescence and in childhood.

\section{Internal consistency and convergent validity}

In terms of internal consistency the NPTQ-C shows convincing results. Both coefficients (alpha and omega) support the reliability of the scale, which is line with other studies where the internal consistency of NPTQ-C also proved to be good (Jellesma et al., 2005; Rieffe et al., 2007).

Convergent validity of NPTQ-C was explored using CFA with a covariates model, and as expected, significant relationship were found with the emotional symptoms factor of SDQ and emotional instability factor of BFQ-C. According to these results ruminative and worrying thoughts are associated with certain emotional symptoms such as nervousness or dysphoric mood, and with feelings of anxiety, depression, discontent or anger. These results are in line with previous studies, emphasizing the link of rumination and worry to internalizing disorders (Aldao et al., 2010), and to some personality traits such as neuroticism (Roelofs et al., 2008). 
Running head: GENDER INVARIANCE AND PSYCHOMETRIC PROPERTIES OF NPTQ-C

We found that the conduct problems factor of SDQ had a significant but weak negative effect on NPTQ-C. These findings may contradict a recent study (McLaughlin, Aldao, Wisco, \& Hilt, 2014) which pointed out that rumination could be related to transitions between internalizing and externalizing disorders, although, the results only related to boys. There are a number of reasons why caution should be applied to the interpretation of the negative relationship between NPTQ-C and the conduct problems factor of SDQ. On the one hand, the internal consistency of the conduct problem subscale is quite low, so its reliability is questionable. On the other hand, other variables, such as emotional symptoms that were controlled for, could easily influence the direction of the relationship between perseverative thoughts and externalizing symptoms.

Furthermore, we measured content-independent perseverative thoughts. Previous studies have found that angry rumination was associated with aggression in questionnaire (Peled \& Moretti, 2010) and experimental studies (Denson, Pedersen, Friese, Hahm, \& Roberts, 2011). Further studies are needed to investigate the associations between conduct problems and perseverative cognitions. This research would be enhanced by using a diverse range of methods and questionnaires to capture the preservative cognitions construct.

The energy factor of BFQ-C in this study was seen to have a weak negative impact on NPTQ-C. Our results are consistent with the findings of Cox and his colleagues (2001), who detected a moderate negative correlation between rumination and extraversion (which is theoretically equivalent to energy) (Barbaranelli et al., 1998; Cox, Enns, Walker, Kjernisted \& Pidlubny, 2001). It is true however, that most of the studies have not found significant relationships between non-productive thoughts and energy/extraversion traits (Bagby \& Parker, 2001; Goldberg, 1992). That said these studies used mainly adult clinical samples (Cox et al., 2001; Bagby \& Parker, 2001). Overall studies exploring the association between rumination and personality traits except neuroticism are sparse, especially among school-aged 
Running head: GENDER INVARIANCE AND PSYCHOMETRIC PROPERTIES OF NPTQ-C

children. Koster and colleagues (2015) suggest that is important to explore the complex dynamics of rumination, since it could lead to social isolation and the avoidance of social stimuli, therefore lower scores on extraversion could even be a consequence of ruminative tendencies. Further prospective studies are needed to clarify the associations between personality traits and rumination (Koster, Fang, \& Marchetti, 2015).

\section{Construct validity}

The design and instruments used in Study 1 did not allow us to test construct validity of the NPTQ-C therefore we conducted Study 2, in which construct validity was explored using the Ruminative Response Scale (Nolen-Hoeksema, 1991). This widely used, self-report measure of rumination was selected intentionally, since it shows good reliability and validity, and it could differentiate between the adaptive (reflective pondering) and the maladaptive (brooding) facets of rumination (Treynor, Gonzalez \& Nolen-Hoeksema, 2003 ). In addition,instead of relying solely on general correlations, we tested the hypothesized associations using CFA with covariates modelling, therefore we were able to test the effects of brooding on NPTQ-C while we controlled for the effects of reflective pondering and vice versa.

We found a significant positive relationship with brooding and reflective pondering subscales of RRS, although the strength of the associations between NPTQ-C and these subscales were considerably different. According to our findings NPTQ-C is weakly associated with the more adaptive self-reflective aspect of rumination, however it shows a strong positive relationship with maladaptive brooding. These findings are completely in line with our previous expectations, and enhance that the nature of thoughts NPTQ-C measures is rather non-productive and maladaptive than constructive.

Although the present study does not aim to provide a large conceptual overview referring to the productive/non-productive or constructive/unconstructive distinction of repetitive 
Running head: GENDER INVARIANCE AND PSYCHOMETRIC PROPERTIES OF NPTQ-C

$\underline{\text { thoughts, it is worthwhile to discuss this question briefly. Previous evidence suggests that }}$ $\underline{\text { many theoretically and operationally overlapping forms of repetitive thinking exist, such as }}$ rumination, worry, anticipatory stress, perseverative cognitions, rehearsal, reflection, problem solving or mental stimulation (Martin \& Tesser, 1996; Papageorgiou \& Wells, 2004; Smith \& Alloy, 2009; Watkins, 2008). These processes could have constructive and unconstructive outcomes; consequently, repetitive thinking could have both consequences. However, according to the theoretical framework of Watkins (2008), we could reliably identify the unconstructive forms of repetitive thinking by three properties; 1) negative valence; 2) negative intrapersonal and situational context in which the repetitive thought occurs; 3 ) abstract level of construal. Using this framework, Watkins (2008) concluded that while depressive rumination, worry and perseverative cognition could be described by negative valence, negative context and abstract construal, reflection could be characterized by positive valence, positive context and abstract construal. For this reason, the former constructs are considered to be unconstructive, but the latter is a potentially constructive form of repetitive thinking.

$\underline{\text { In light of the above, NPTQ-C seems to measure non-productive/unconstructive thoughts, }}$ since most of its items are negatively valenced (e.g.: "...bad things will happen", "I am worried..."), and the situational context in which the thoughts occur are also negative (e.g.: "when I have a problem...", "when I make a mistake..."). In addition, the statements reflect an abstract level of processing, where the focus is on the desirability and importance of outcomes instead of the feasibility or planning of outcomes (e.g.: "...I will only make things worse" "...why me?").

In general, our findings concur with previous research that NPTQ-C has good psychometric properties (Jellesma et al., 2005; Rieffe et al., 2007). Specifically, our findings show that NPTQ-C is also a reliable and applicable scale for use in adolescent populations. 
Running head: GENDER INVARIANCE AND PSYCHOMETRIC PROPERTIES OF NPTQ-C

On the basis of the invariance analysis, we suggest it is also well placed in studies to detect any gender differences that might exist.

\section{Limitations}

The study has a number of limitations. First, despite most of the empirical and theoretical findings which distinguish rumination and worry (Fresco et al., 2002; Watkins, 2004), our study measured the two constructs in the same instrument. It could be argued that measuring rumination and worry together was a weakness since most of the empirical and theoretical findings place them as separate concepts. However, given the high correlations between these and their overlapping roles in the development of MDD and GAD (Aldao et al., 2010), we are convinced that this decision is well-established. A second limitation relates to our inability to confirm test-retest reliability as data collection was not repeated.

\section{Conclusion}

It is essential to detect the early signs of maladaptive thoughts so that preventive efforts can work towards the avoidance of subsequent disorders including depression, anxiety or somatic health complaints (Jellesma et al., 2009; Muris et al., 2004). Moreover, a recent systematic review and meta-analysis (Clancy, Prestwich, Caperon \& O'Connor, 2016) identified an indirect pathway from perseverative cognitions to disease outcomes: the health behaviours. Clancy et al. (2016) found that perseverative cognitions were associated with increases in health risk behaviours such as substance use, unhealthy eating, smoking or alcohol consumption. These findings also highlight the importance of the early mapping of 
Running head: GENDER INVARIANCE AND PSYCHOMETRIC PROPERTIES OF NPTQ-C

non-productive thoughts/perseverative cognitions and we think, that the availability of valid and reliable instruments designed specifically for children/adolescents are paramount to this endeavour.

This study draws attention to an under tested measurement, the NPTQ-C. This questionnaire, which was designed to capture ruminative and worrying thoughts of children and adolescents, was found to show good psychometric properties. In addition it is able to delineate perseverative cognitions across gender if differences exist.

Future work to develop new instruments, should take into account the need to understand the content of the perseverative cognitions (Martin \& Tesser, 1996; Nolen-Hoeksema et al., 2008) as well as being to measure their prevalence.

\section{References}

Abela, J. R. Z., Brozina, K., \& Haigh, E. P. (2002). An examination of the response styles theory of depression in third- and seventh-grade children: A short-term longitudinal study. Journal of Abnormal Child Psychology, 30(5), 515-527. doi:10.1023/a:1019873015594

Abela, J. R. Z., Vanderbilt, E., \& Rochon, A. (2004). A test of the integration of the response styles and social support theories of depression in third and seventh grade children. 
Running head: GENDER INVARIANCE AND PSYCHOMETRIC PROPERTIES OF NPTQ-C

Journal of Social and Clinical Psychology, 23(5), 653-674. doi:10.1521/jscp.23.5.653.50752

Aldao, A., Nolen-Hoeksema, S., \& Schweizer, S. (2010). Emotion-regulation strategies across psychopathology: A meta-analytic review. Clinical Psychology Review, 30(2), $217-$ 237. doi:10.1016/j.cpr.2009.11.004

Asparouhov, T., \& Muthen, B. (2006). Robust Chi Square Dierence Testing with Mean and Variance Adjusted Test Statistics. Mplus Web Notes, 10. http://www.statmodel.com/examples/webnote.shtml

Bagby, R. M. \& Parker, J. D. A. (2001). Relation of Rumination and Distraction with Neuroticism and Extraversion in a Sample of Patients with Major Depression. Cognitive Therapy and Research, 25(1), 91-102.

Barbaranelli, C., Caprara, G. V., Rabasca, A., \& Pastorelli, C. (2003). A questionnaire for measuring the Big Five in late childhood. Personality and Individual Differences, 34(4), 645-664. doi:10.1016/s0191-8869(02)00051-x

Beckwe, M., \& Deroost, N. (2015). Attentional biases in ruminators and worriers. Psychological Research. doi:10.1007/s00426-015-0703-8

Borkovec, T. D., Ray, W. J., \& Stober, J. (1998). Worry: A cognitive phenomenon intimately linked to affective, physiological, and interpersonal behavioral processes. Cognitive Therapy and Research, 22(6), 561-576. doi:10.1023/a:1018790003416

Bowen, N. K., \& Guo, S. (2012). Structural equation modeling. Pocket Guide to Social Work Research Methods. New York.: Oxford University Press.

Brosschot, J. F., Pieper, S., \& Thayer, J. F. (2005). Expanding stress theory: prolonged activation and perseverative cognition. Psychoneuroendocrinology, 30(10), 10431049. http://doi.org/10.1016/j.psyneuen.2005.04.008 
Running head: GENDER INVARIANCE AND PSYCHOMETRIC PROPERTIES OF NPTQ-C

Brosschot, J. F., Gerin, W., \& Thayer, J. F. (2006). The perseverative cognition hypothesis: A review of worry, prolonged stress-related physiological activation, and health. Journal of Psychosomatic Research, 60(2), 113-124. doi:10.1016/j.jpsychores.2005.06.074

Brown, T. A. (2006). Confirmatory factor analysis for applied research. New York: Guilford Press.

Carter, J. A. (2010). Worry and Rumination: Measurement Invariance Across Gender. (Doctoral dissertation). All Graduate Theses and Dissertations, Paper 805., Utah State Univesity. Retrieved from http://digitalcommons.usu.edu/etd/805

Carter, J. A. \& Bates, S. C. (2013). The Penn State Worry Questionnaire: Comparative Model Fit and Invariance across Gender. National Forum Journal Of Counseling And Addiction, 2(1), 1-25.

Chen, F. F. (2007). Sensitivity of goodness of fit indexes to lack of measurement invariance. Structural Equation Modeling-a Multidisciplinary Journal, 14(3), 464-504.

Cheung, G. W., \& Rensvold, R. B. (2002). Evaluating goodness-of-fit indexes for testing measurement invariance. Structural Equation Modeling, 9(2), 233-255. doi:10.1207/s15328007sem0902_5

Clancy, F., Prestwich, A., Caperon, L., \& O’Connor, D. B. (2016). Perseverative Cognition and Health Behaviors: A Systematic Review and Meta-Analysis. Frontiers in Human Neuroscience, 10, 534. https://doi.org/10.3389/fnhum.2016.00534

Cox, B. J., Enns, M. W., Walker, J. R., Kjernisted, K. \&Pidlubny, S. R. (2001). Psychological vulnerabilities in patients with major depression vs panic disorder. Behaviour Research and Therapy, 39, 567-573.

Denson, T. F., Pedersen, W. C., Friese, M., Hahm, A., \& Roberts, L. (2011). Understanding Impulsive Aggression: Angry Rumination and Reduced Self-Control Capacity Are 
Running head: GENDER INVARIANCE AND PSYCHOMETRIC PROPERTIES OF NPTQ-C

Mechanisms Underlying the Provocation-Aggression Relationship. Personality and Social Psychology Bulletin, 37(6), 850-862. doi:10.1177/0146167211401420

Dimitrov, D. M. (2010). Testing for Factorial Invariance in the Context of Construct Validation. Measurement and Evaluation in Counseling and Development, 43(2), 121149. doi:10.1177/0748175610373459

Fresco, D. M., Frankel, A. N., Mennin, D. S., Turk, C. L., \& Heimberg, R. G. (2002). Distinct and overlapping features of rumination and worry: The relationship of cognitive production to negative affective states. Cognitive Therapy and Research, 26(2), 179188. doi:10.1023/a:1014517718949

Garnefski, N., Rieffe, C., Jellesma, F., Terwogt, M. M., \& Kraaij, V. (2007). Cognitive emotion regulation strategies and emotional problems in 9-11-year-old children - The development of an instrument. European Child \& Adolescent Psychiatry, 16(1), 1-9. doi:10.1007/s00787-006-0562-3

Goldberg, L. R. (1992). The development of markers for the Big-Five factor structure. Psychological Assessment, 4, 26-42.

Goodman, R., Meltzer, H., \& Bailey, V. (1998). The strengths and difficulties questionnaire: A pilot study on the validity of the self-report version. European Child \& Adolescent Psychiatry, 7(3), 125-130.

Hoyer, J., Gloster, A. T., \& Herzberg, P. Y. (2009). Is worry different from rumination? Yes, it is more predictive of psychopathology! GMS Psycho-Social-Medicine, 6. http://doi.org/10.3205/psm000062

Hsu, K. J., Beard, C., Rifkin, L., Dillon, D. G., Pizzagalli, D. A., \& Bjorgvinsson, T. (2015). Transdiagnostic mechanisms in depression and anxiety: The role of rumination and attentional control. Journal of Affective Disorders, 188, 22-27. doi:10.1016/j.jad.2015.08.008 
Running head: GENDER INVARIANCE AND PSYCHOMETRIC PROPERTIES OF NPTQ-C

Jellesma, F. C. (2008). Somatic Complaints in Childhood: How they are related to children's emotional and social functioning. Doctoral Thesis. Leiden University. Retrieved from: http://www.acqol.com.au/publications/resources/thesis-jellesma-f.pdf

Jellesma, F. C., Meerum Terwogt, M., Reijntjes, A. H., Rieffe, C. J., \& Stegge, H. (2005). De vragenlijst Non-Productieve Denkprocessen voor Kinderen. [Non-Productive Thoughts Questionnaire for Children: Worrying and Rumination]. Kind en adolescent, 26(4), 171-177.

Jellesma, F. C., Verkuil, B., \& Brosschot, J. F. (2009). Postponing worrisome thoughts in children: The effects of a postponement intervention on perseverative thoughts, emotions and somatic complaints. Social Science \& Medicine, 69(2), 278-284. doi:10.1016/j.socscimed.2009.04.031

Johnson, D. P., \& Whisman, M. A. (2013). Gender differences in rumination: A metaanalysis. Personality and Individual Differences, 55(4), 367-374. doi:10.1016/j.paid.2013.03.019

Jose, P. E., \& Brown, I. (2008). When does the gender difference in rumination begin? Gender and age differences in the use of rumination by adolescents. Journal of Youth and Adolescence, 37(2), 180-192. doi:10.1007/s10964-006-9166-y

Kökönyei, Gy., Jozan, A., Morgan, A., Szemenyei, E., Urban, R., Reinhardt, M., \& Demetrovics, Zs. (2015). Perseverative thoughts and subjective health complaints in adolescence: Mediating effects of perceived stress and negative affects. Psychology \& Health, 30(8), 969-986. doi:10.1080/08870446.2015.1007982

Koster, E. H. W., Fang, L., \& Marchetti, I. (2015). Self-Regulation Through Rumination: Consequences and Mechanisms. In G. H. E. Gendolla, M. Tops, \& S. L. Koole (Eds.), Handbook of Biobehavioral Approaches to Self-Regulation (pp. 371-383). Springer 
Running head: GENDER INVARIANCE AND PSYCHOMETRIC PROPERTIES OF NPTQ-C

New York. Retrieved from http://link.springer.com/chapter/10.1007/978-1-4939-1236$0 \lcm{24}$

Lopez, C. M., Driscoll, K. A., \& Kistner, J. A. (2009). Sex Differences and Response Styles: Subtypes of Rumination and Associations with Depressive Symptoms. Journal of Clinical Child and Adolescent Psychology, 38(1), 27-35. doi:10.1080/15374410802575412

Martin, L. L., \& Tesser, A. (1996). Some Ruminative Thoughts. In R. S. Wyer (Ed.), Ruminative Thoughts. Advances in Social Cognition, Volume IX (pp. 1-48). New Jersey: Lawrence Erlbaum Associates.

McLaughlin, K. A., Aldao, A., Wisco, B. E., \& Hilt, L. M. (2014). Rumination as a Transdiagnostic Factor Underlying Transitions Between Internalizing Symptoms and Aggressive Behavior in Early Adolescents. Journal of Abnormal Psychology, 123(1), 13-23. doi:10.1037/a0035358

McLaughlin, K. A., Borkovec, T. D., \& Sibrava, N. J. (2007). The effects of worry and rumination on affect states and cognitive activity. Behavior Therapy, 38(1), 23-38. doi:10.1016/j.beth.2006.03.003

McLean, C. P., Asnaani, A., Litz, B. T., \& Hofmann, S. G. (2011). Gender differences in anxiety disorders: Prevalence, course of illness, comorbidity and burden of illness. Journal of Psychiatric Research, 45(8), 1027-1035. doi:10.1016/j.jpsychires.2011.03.006

Meade, A. W., Johnson, E. C., \& Braddy, P. W. (2008). Power and sensitivity of alternative fit indices in tests of measurement invariance. The Journal of Applied Psychology, 93(3), 568-592. http://doi.org/10.1037/0021-9010.93.3.568 
Running head: GENDER INVARIANCE AND PSYCHOMETRIC PROPERTIES OF NPTQ-C

Milfont, T. L., \& Fischer, R. (2010). Testing measurement invariance across groups: Applications in cross-cultural research. International Journal of Psychological Research, 3(1), 111-121.

Muris, P., Roelofs, J., Meesters, C., \& Boomsma, P. (2004). Rumination and worry in nonclinical adolescents. Cognitive Therapy and Research, 28(4), 539-554. doi:10.1023/B:COTR.0000045563.66060.3e

Muthén, L. K., \& Muthén, B. O. (1998-2010). Mplus User's Guide. Sixth Edition. Los Angeles, CA: Muthén \& Muthén.

Nolen-Hoeksema, S. (1991). Responses to depression and their effects on the duration of depressive episodes. Journal of Abnormal Psychology, 100(4), 569-582.

Nolen-Hoeksema, S. (2012). Emotion Regulation and Psychopathology: The Role of Gender. Annual Review of Clinical Psychology,8(8), 161-187. doi:10.1146/annurev-clinpsy032511-143109

Nolen-Hoeksema, S., \& Aldao, A. (2011). Gender and age differences in emotion regulation strategies and their relationship to depressive symptoms. Personality and Individual Differences, 51(6), 704-708. doi:10.1016/j.paid.2011.06.012

Nolen-Hoeksema, S., \& Davis, C. G. (1999). "Thanks for sharing that": ruminators and their social support networks. Journal of Personality and Social Psychology, 77(4), 801814.

Nolen-Hoeksema, S., \& Jackson, B. (2001). Mediators of the gender difference in rumination. Psychology of Women Quarterly, 25(1), 37-47. doi:10.1111/1471-6402.00005

Nolen-Hoeksema, S., Wisco, B. E., \& Lyubomirsky, S. (2008). Rethinking Rumination. Perspectives on Psychological Science, 3(5), 400-424. doi:10.1111/j.17456924.2008.00088.x 
Running head: GENDER INVARIANCE AND PSYCHOMETRIC PROPERTIES OF NPTQ-C

Nolen-Hoeksema, S., \& Morrow, J. (1993). Effects Of Rumination And Distraction On Naturally-Occurring Depressed Mood. Cognition \& Emotion, 7(6), 561-570. doi:10.1080/02699939308409206

Ottaviani, C., Thayer, J. F., Verkuil, B., Lonigro, A., Medea, B., Couyoumdjian, A., \& Brosschot, J. F. (2016). Physiological concomitants of perseverative cognition: A systematic review and meta-analysis. Psychological Bulletin, 142(3), 231-259. http://doi.org/10.1037/bul0000036

Papageorgiou, C., \& Wells, A. (2004). Nature, Functions and Beliefs about Depressive Rumination. In Papageorgiou, C., \& Wells, A. (Eds.), Depressive Rumination: Nature, Theory and Treatment (pp. 3-20). Chichester: John Wiley \& Sons Ltd.

Parker, G., Fletcher, K., Paterson, A., Anderson, J., \& Hong, M. (2014). Gender differences in depression severity and symptoms across depressive sub-types. Journal of Affective Disorders, 167, 351-357. doi:10.1016/j.jad.2014.06.018

Peled, M., \& Moretti, M. M. (2010). Ruminating on Rumination: are Rumination on Anger and Sadness Differentially Related to Aggression and Depressed Mood? Journal of Psychopathology and Behavioral Assessment, 32(1), 108-117. doi:10.1007/s10862009-9136-2

Rieffe, C., Terwogt, M. M., Petrides, K. V., Cowan, R., Miers, A. C., \& Tolland, A. (2007). Psychometric properties of the Emotion Awareness Questionnaire for children. Personality and Individual Differences, 43(1), 95-105. doi:10.1016/j.paid.2006.11.015

Roelofs, J., Huibers, M., Peeters, F., Arntz, A., \& van Os, J. (2008). Rumination and worrying as possible mediators in the relation between neuroticism and symptoms of depression and anxiety in clinically depressed individuals. Behaviour Research and Therapy, 46(12), 1283-1289. doi:10.1016/j.brat.2008.10.002 
Running head: GENDER INVARIANCE AND PSYCHOMETRIC PROPERTIES OF NPTQ-C

Rózsa, S. (2005). A BFQ-C pszichometriai jellemzőinek hazai vizsgálata, a normák kialakítása [Testing of the psychometric properties of BFQ-C and forming of norms] In.: Barbaranelli, C., Caprara, G. V., Rabasca, A. (2004). BFQ-C Big Five Questionnaire Children, Kézikönyv. Budapest: OS Hungary Kft.

Segerstrom, S. C., Tsao, J. C. I., Alden, L. E., \& Craske, M. G. (2000). Worry and rumination: Repetitive thought as a concomitant and predictor of negative mood. Cognitive Therapy and Research, 24(6), 671-688. doi:10.1023/a:1005587311498

Smith, J. M., \& Alloy, L. B. (2009). A roadmap to rumination: A review of the definition, assessment, and conceptualization of this multifaceted construct. Clinical Psychology Review, 29(2), 116-128. doi:10.1016/j.cpr.2008.10.003

Trapnell, P. D., \& Campbell, J. D. (1999). Private self-consciousness and the five-factor model of personality: Distinguishing rumination from reflection. Journal of Personality and Social Psychology, 76(2), 284-304. doi:10.1037/0022-3514.76.2.284

Treynor, W., Gonzalez, R., \& Nolen-Hoeksema, S. (2003). Rumination Reconsidered: A Psychometric Analysis. Cognitive Therapy and Research, 27(3), 247-259. https://doi.org/10.1023/A:1023910315561

Turi, E., Gervai, J., Aspan, N., Halasz, J., Nagy, P., \& Gadoros, J. (2013). [Validation of the Hungarian version of the Strengths and Difficulties Questionnaire in an adolescent clinical population]. Psychiatria Hungarica, 28(2), 165-179.

Verkuil, B., Brosschot, J. F., de Beurs, D. P., \& Thayer, J. F. (2009). Effects of explicit and implicit perseverative cognition on cardiac recovery after cognitive stress. International Journal of Psychophysiology, 74, 220-228. Retrieved from: http://www.sciencedirect.com/science/article/pii/S0167876009002232 
Running head: GENDER INVARIANCE AND PSYCHOMETRIC PROPERTIES OF NPTQ-C

Watkins, E. (2004). Appraisals and strategies associated with rumination and worry. Personality and Individual Differences, 37(4), 679-694. doi:10.1016/j.paid.2003.10.002

Watkins, E. R. (2008). Constructive and Unconstructive Repetitive Thought. Psychological Bulletin, 134(2), 163-206. https://doi.org/10.1037/0033-2909.134.2.163

Young, C. C., \& Dietrich, M. S. (2015). Stressful life events, worry, and rumination predict depressive and anxiety symptoms in young adolescents. Journal of Child and Adolescent Psychiatric Nursing, 28(1), 35-42. doi:10.1111/jcap.12102

Table 1.

Standardized Factor Loadings from Confirmatory Factor Analysis of NPTQ-C

Item

1. I am often worried.

2. When I have a problem, I often think "why me?"

3. It is difficult to forget bad things.

4. Problems never worry me. I just solve them.

5. When I have a problem, I can't stop thinking about it.

$.701^{*}$

6. When I make a mistake, I am worried about what might happen.

7. When I have a problem, I think about it all the time.

$.779 *$

8. When I try to deal with a problem, I am worried that I will only make things worse.
Standardized factor loadings 
Running head: GENDER INVARIANCE AND PSYCHOMETRIC PROPERTIES OF NPTQ-C

9. When I have a problem, I often think about how bad it is.

$.753^{*}$

10. When I don't know exactly what is happening, I usually $.584 *$ think that bad things will happen.

Note. NPTQ-C= Non-Productive Thoughts Questionnaire for Children;

$* \mathrm{p}<.001$

Table 2.

Testing measurement invariance

\begin{tabular}{|l|c|c|l|l|l|l|l|l|l|}
\hline & $\chi^{2}$ & df & RMSEA & CFI & $\Delta \chi^{2}$ & $\Delta d f$ & $p$ & $\Delta R M S E A$ & $\Delta C F I$ \\
\hline \multicolumn{7}{|c|}{ CFA in each group separately } \\
\hline Girls & 74.305 & 33 & .040 & .978 & & \\
\hline Boys & 58.179 & 33 & .032 & .990 & & \\
\hline $\begin{array}{l}\text { Multigroup analyses to test the measurement invariance } \\
\text { invariance }\end{array}$ & 129.150 & 66 & .035 & .985 & - & - & $<.001$ & \\
\hline $\begin{array}{l}\text { Configural } \\
\text { Configural } \\
\text { versus Metric } \\
\text { invariance }\end{array}$
\end{tabular}


Running head: GENDER INVARIANCE AND PSYCHOMETRIC PROPERTIES OF NPTQ-C

\begin{tabular}{|c|c|c|c|c|c|c|c|c|c|}
\hline $\begin{array}{l}\text { Metric versus } \\
\text { Scalar } \\
\text { invariance }\end{array}$ & & & & & 18.553 & 9 & $<.05$ & -.001 & $<.001$ \\
\hline $\begin{array}{l}\text { Scalar } \\
\text { invariance }\end{array}$ & 154.759 & 84 & .033 & .983 & 9.984 & 9 & $<.05$ & & \\
\hline
\end{tabular}

$\mathrm{CFI}=$ comparative fit index; $\Delta \chi^{2}=\chi^{2}$ difference test calculated with difftest procedure.

Table 3.

Means, standard deviations and effect sizes by gender group with Cronbach's alphas

\begin{tabular}{|c|c|c|c|c|c|}
\hline Variable $(\alpha)$ & $\begin{array}{c}\text { Total } \\
\text { sample } \\
\text { M (SD) }\end{array}$ & $\begin{array}{l}\text { Boys } \\
\text { M (SD) }\end{array}$ & $\begin{array}{c}\text { Girls } \\
\text { M (SD) }\end{array}$ & $\mathrm{t}(\mathrm{p})$ & $\begin{array}{c}\text { Effect } \\
\text { size } \\
\text { Cohen d }\end{array}$ \\
\hline $\begin{array}{l}\text { Non-Productive } \\
\text { Thoughts Questionnaire } \\
\text { for Children - NPTQ-C } \\
\qquad(\alpha=.83)\end{array}$ & $\begin{array}{l}19.64 \\
(4.55)\end{array}$ & $\begin{array}{l}18.23 \\
(4.29)\end{array}$ & $\begin{array}{l}20.99 \\
(4.37)\end{array}$ & $\begin{array}{c}12.44 \\
(<.001)\end{array}$ & 0.64 \\
\hline $\begin{array}{l}\text { Emotional symptoms - } \\
\text { SDQ } \\
(\alpha=.68)\end{array}$ & $\begin{array}{c}3.13 \\
(2.27)\end{array}$ & $\begin{array}{c}2.35 \\
(1.99)\end{array}$ & $\begin{array}{c}3.86 \\
(2.29)\end{array}$ & $\begin{array}{c}13.65 \\
(<.001)\end{array}$ & 0.70 \\
\hline $\begin{array}{c}\text { Conduct problems - } \\
\text { SDQ } \\
(\alpha=.45)\end{array}$ & $\begin{array}{c}2.67 \\
(1.59)\end{array}$ & $\begin{array}{c}2.72 \\
(1.67)\end{array}$ & $\begin{array}{c}2.62 \\
(1.52)\end{array}$ & $\begin{array}{c}1.23 \\
(<.001)\end{array}$ & 0.06 \\
\hline $\begin{array}{l}\text { Hyperactivity/inattention } \\
\qquad \begin{array}{l}\text { - SDQ } \\
(\alpha=.59)\end{array}\end{array}$ & $\begin{array}{l}4.14 \\
(2.09)\end{array}$ & $\begin{array}{c}3.92 \\
(2.05)\end{array}$ & $\begin{array}{l}4.35 \\
(2.11)\end{array}$ & $\begin{array}{c}3.98 \\
(<.001)\end{array}$ & 0.21 \\
\hline
\end{tabular}


Running head: GENDER INVARIANCE AND PSYCHOMETRIC PROPERTIES OF NPTQ-C

$$
\begin{gathered}
\text { Peer relationship } \\
\text { problems - SDQ } \\
\quad(\alpha=.54)
\end{gathered}
$$

Prosocial behaviour -

$$
\begin{gathered}
\text { SDQ } \\
(\alpha=.64) \\
\text { rgy }- \text { BF } \\
(\alpha=.83)
\end{gathered}
$$$$
\text { Energy - BFQ-C }
$$

Agreeableness - BFQ-C

$$
(\alpha=.85)
$$

45.56

$(8.12)$

7.02
$(4.55)$

6.60

(1.92)

48.46

(7.82)

48.24

$(8.17)$

\subsection{4}

(8.07)

43.59

(8.47)

43.64

(8.44)

$(\alpha=.86)$

Emotional instability -

$$
\text { BFQ-C }
$$

$(\alpha=.88)$

Openness - BFQ-C

$(\alpha=.79)$
36.93
$(9.89)$

35.20

(9.46)

44.15

(7.83)
44.76

(7.69)
1.93

(1.67)

4.55

$(<.001)$

0.23

7.41
$(1.78)$

\subsection{1}

$(<.001)$

0.44

48.65

(7.51)

0.89

$(>.05)$

0.05

\subsection{1}

(7.99)

\subsection{6}

$(<.001)$

0.31

$$
43.54
$$

$(8.51)$

0.21

0.01

Note. NPTQ-C= Non-Productive Thoughts Questionnaire for Children; SDQ= Strength and

Difficulties Questionnaire, BFQ-C= Big Five Questionnaire for Children 
Running head: GENDER INVARIANCE AND PSYCHOMETRIC PROPERTIES OF NPTQ-C

Table 4.

Bonferroni corrected correlations between NPTQ-C, SDQ and BFQ-C along with Cronbach alphas

\begin{tabular}{|c|c|c|c|c|c|c|}
\hline \multirow[t]{2}{*}{ NPTQ-C } & BFQ-C & BFQ-C & BFQ-C & BFQ-C & BFQ-C & Cronbach's \\
\hline & Extraversion & Agreeableness & Conscientiousness & $\begin{array}{l}\text { Emotional } \\
\text { instability }\end{array}$ & Openness & alpha \\
\hline
\end{tabular}

\section{NPTQ-C}

$-.20 * *$

$-.067^{*}$

$-.181 * *$

$.525 * *$

$-.213 * *$

.83

$\underline{\text { SDQ }}$

Emotiona

$$
.622 * *
$$

$-.212 * *$

$-.380$

$-.141 * *$

$.583 * *$

$-.203 * *$

.68

symptoms

Conduct

$.226^{* *}$

.001

$-.202 * *$

$-.272 * *$

$.557 * *$

$-.154 * *$

.45

problems 
Running head: GENDER INVARIANCE AND PSYCHOMETRIC PROPERTIES OF NPTQ-C

\begin{tabular}{cccccccc}
\hline $\begin{array}{c}\text { Hyperactivi } \\
\text { ty/inattentio } \\
\mathrm{n}\end{array}$ & $.307^{* *}$ & .011 & $-.112^{* *}$ & $-.402^{* *}$ & $.422^{* *}$ & $-.272^{* *}$ & .59 \\
$\begin{array}{c}\text { Peer } \\
\text { relation } \\
\text { problems }\end{array}$ & $.218^{* *}$ & $-.312^{* *}$ & $-.260^{* *}$ & $-.107^{* *}$ & $.292^{* *}$ & $-.095^{* *}$ & .54 \\
& & & & & & & \\
\\
$\begin{array}{c}\text { Prosocial } \\
\text { behaviour }\end{array}$ & .06 & $.359^{* *}$ & $.608^{* *}$ & $.390^{* *}$ & $-.78^{* *}$ & $.319^{* *}$ & .64 \\
& & & & & & & \\
\\
$\begin{array}{c}\text { Cronbach's } \\
\text { alpha }\end{array}$
\end{tabular}

Note. NPTQ-C= Non- Productive Thoughts Questionnaire for Children; SDQ= Strength and Difficulties Questionnaire; BFQ-C= Big Five Questionnaire for Children. $\mathrm{p}<.05^{*} ; \mathrm{p}<.001^{* *}$ 
Running head: GENDER INVARIANCE AND PSYCHOMETRIC PROPERTIES OF NPTQ-C

Table 5.

Standardized regression weights between NPTQ-C, subscales of SDQ and BFQ-C controlled for age and gender

\begin{tabular}{ccc}
\hline Explanatory variables & Model 1 & Model 2 \\
Gender & $.319^{* * * *}$ & $.099^{* * *}$ \\
Age & $.199^{* * *}$ & .042 \\
Emotional symptoms - SDQ & $.464 * * *$ \\
Conduct problems - SDQ & $-.118^{*}$ \\
Hyperactivity/inattention - SDQ & $.043^{* *}$ \\
Peer relationship problems -SDQ & $-.070^{* *}$ \\
Prosocial behaviour - SDQ & .045 \\
Energy - BFQ-C & $-.147^{* *}$ \\
Agreeableness - BFQ -C
\end{tabular}


Running head: GENDER INVARIANCE AND PSYCHOMETRIC PROPERTIES OF NPTQ-C

$$
\text { Conscientiousness - BFQ-C }
$$

Emotional instability - BFQ-C $.364 * * *$

$$
\text { Openness - BFQ-C }
$$

$$
R^{2}
$$

Note. NPTQ-C= Non- Productive Thoughts Questionnaire for Children; SDQ= Strength and Difficulties Questionnaire; BFQ-C= Big Five Questionnaire for Children.

$\mathrm{p}<.05^{*} ; \mathrm{p}<.01 * * ; \mathrm{p}<.001 * * *$

\begin{tabular}{|c|c|c|c|c|c|}
\hline Variable $(\alpha)$ & $\begin{array}{c}\text { Total } \\
\text { sample } \\
\text { M (SD) }\end{array}$ & $\begin{array}{l}\text { Boys } \\
\text { M (SD) }\end{array}$ & $\begin{array}{c}\text { Girls } \\
\text { M (SD) }\end{array}$ & $\mathrm{t}(\mathrm{p})$ & $\begin{array}{c}\text { Effect } \\
\text { size } \\
\text { Cohen d }\end{array}$ \\
\hline $\begin{array}{c}\text { NPTQ-C } \\
(\alpha=.81)\end{array}$ & $\begin{array}{l}18.80 \\
(4.19)\end{array}$ & $\begin{array}{l}17.05 \\
(3.69)\end{array}$ & $\begin{array}{l}19.71 \\
(4.16)\end{array}$ & $\begin{array}{c}6.47 \\
(<.001)\end{array}$ & 0.67 \\
\hline $\begin{array}{l}\text { Brooding-RRS } \\
\qquad(\alpha=.68)\end{array}$ & $\begin{array}{l}20.20 \\
(5.08)\end{array}$ & $\begin{array}{c}9.36 \\
(2.75)\end{array}$ & $\begin{array}{l}10.52 \\
(2.82)\end{array}$ & $\begin{array}{c}3.90 \\
(<.001)\end{array}$ & 0.46 \\
\hline $\begin{array}{l}\text { Reflective pondering- } \\
\text { RRS } \\
(\alpha=.73)\end{array}$ & $\begin{array}{l}10.04 \\
(3.15)\end{array}$ & $\begin{array}{c}9.31 \\
(2.90)\end{array}$ & $\begin{array}{l}10.43 \\
(3.21)\end{array}$ & $\begin{array}{c}3.40 \\
(<.001)\end{array}$ & 0.36 \\
\hline $\begin{array}{l}\text { RRS Total } \\
\qquad(\alpha=.77)\end{array}$ & $\begin{array}{l}10.12 \\
(2.84)\end{array}$ & $\begin{array}{l}18.72 \\
(4.62)\end{array}$ & $\begin{array}{l}20.98 \\
(5.15)\end{array}$ & $\begin{array}{c}4.28 \\
(<.001)\end{array}$ & 0.42 \\
\hline
\end{tabular}

Table 6.

Means, standard deviations and effect sizes by gender group with Cronbach's alphas

Note. NPTQ-C= Non-Productive Thoughts Questionnaire for Children; RRS= Ruminative Response Scale 
Running head: GENDER INVARIANCE AND PSYCHOMETRIC PROPERTIES OF NPTQ-C

Table 7.

Bonferroni corrected correlations between NPTQ-C, Brooding and Reflective pondering subscales of RRS.

\begin{tabular}{|c|c|c|c|c|}
\hline & NPTQ-C & $\begin{array}{l}\text { Brooding- } \\
\text { RRS }\end{array}$ & $\begin{array}{c}\text { Reflective } \\
\text { pondering- } \\
\text { RRS }\end{array}$ & RRS Total \\
\hline NPTQ-C & 1.000 & & & \\
\hline Brooding- RRS & $.605 * *$ & 1.000 & & \\
\hline $\begin{array}{l}\text { Reflective Pondering- } \\
\text { RRS }\end{array}$ & $.364 * *$ & $.418 * *$ & 1.000 & \\
\hline RRS Total & $.561 * *$ & $.803 * *$ & $.864 * *$ & 1.000 \\
\hline \multicolumn{5}{|c|}{$\begin{array}{l}\text { Note. } \text { NPTQ-C }=\text { Non-Productive Thoughts Questionnaire for Children; RRS }=\text { Ruminative } \\
\text { Response Scale }\end{array}$} \\
\hline
\end{tabular}


Running head: GENDER INVARIANCE AND PSYCHOMETRIC PROPERTIES OF NPTQ-C

Table 8.

Standardized regression weights between NPTQ-C, Brooding and Reflective pondering subscales of RRS controlled for age and gender

Explanatory variables

standardized regression

weights

Gender

Age

Brooding-RRS

Reflective pondering- RRS

$R^{2}$
$.194 * * *$

$$
.073
$$

$.643^{* * *}$

$.101 *$

.582

Note. NPTQ-C $=$ Non- Productive Thoughts Questionnaire for Children; RRS= Ruminative Response Scale. 
Running head: GENDER INVARIANCE AND PSYCHOMETRIC PROPERTIES OF NPTQ-C

$\mathrm{p}<.05^{*} ; \mathrm{p}<.01 * * ; \mathrm{p}<.001 * * *$. 